\title{
HUBUNGAN PELAYANAN DOKTER TERHADAP PERSEPSI MUTU PASIEN PESERTA BPJS DI INSTALASI RAWAT JALAN RSUD ARIFIN ACHMAD PEKANBARU TAHUN 2015
}

\author{
Jihan Natassa, Desma Arviana \\ STIKes Hang Tuah Pekanbaru \\ Email: jihannatassa@yahoo.co.id
}

\begin{abstract}
According to indonesian lawno.44 2009 article 2 about the hospital said that hospitals must remain capableimprove services of better quality to fulfilledhighest degree of health. While according to indonesianlaw no 24 states that in 2011 about BPJS,BPJS aimed to provide certainty for social protection and welfare of all the people.The purpose of this research is to know the relationship of doctor servicesagainst the perception of patient qualityparticipants of BPJS in outpatient installation ArifinAchmad Hospital Pekanbaru 2015.

The kind of this research is analytic quantitative research, with a design cross sectional. Research carried out time for the month ofmay-june 2015. Total Sample are 196 peopleswhichisthe participants of BPJS who is visiting outpatientinstallation in ArifinAchmad Hospital Pekanbaru. The sample collection technique is accidental of sampling Analysis that been used is bivariat and univariat.

From the results of research shows that there is meaningful relationship between medical doctor skills with perception of patients $p$ value $=0,005$ ( $p<$ alpha 0,05), The attitude of the doctor with patientsperception $p$ value $=$ 0,000 ( $p<$ alpha 0,05), Information dissemination doctor with patientsperceptionp value $=0,004$ ( $p<a$ alpha $0,05)$, Punctuality of doctorservicesp value $=0,005$ ( $p<$ alpha 0,05).

Can be concluded that there is the relationship between doctor services against the perception of patientqualityparticipants of BPJS in outpatient installation ArifinAchmad Hospital Pekanbaru. Hence it is expected to chairman of hospital management in order to repair and improve quality of service doctor.
\end{abstract}

Keyword: Quality of Doctor Service, Perception, BPJS Out patient

\section{PENDAHULUAN}

Menurut UU RI No. 44 tahun 2009 pasal 2 tentang rumah sakit bahwa rumah sakit adalah institusi pelayanan kesehatan bagi masyarakat dengan karakteristik tersendiri yang dipengaruhi oleh perkembangan ilmu pengetahuan kesehatan, kemajuan teknologi dan kehidupan sosial ekonomi masyarakat yang harus tetap mampu meningkatkan pelayanan yang lebih bermutu dan terjangkau oleh masyarakat agar terwujud derajat kesehatan yang setinggitingginya. Mutu adalah perpaduan sifat-sifat dan karakteristik produk atau jasa yang dapat memenuhi kebutuhan pemakai atau pelanggan. Deming (1980) mengemukakan bahwa mutu dapat dilihat dari aspek persepsi pelanggan, serta kebutuhan dan keinginan pelanggan. Dari aspek persepsi pelanggan, mutu adalah penilaian subjektif pelanggan. Persepsi pelanggan dapat berubah karena pengaruh berbagai hal seperti iklan, reputasi produk atau jasa yang dihasilkan, pengalaman dan sebagainya. Dari aspek kebutuhan dan keinginan pelanggan, mutu adalah apa yang dikehendaki dan dibutuhkan oleh pelanggan (Bustami, 2011).

Dokter sebagai kunci penting dalam pelayanan dirumah sakit mempunyai peran strategis dan unik, apalagi bila mengingat tingkat pendidikan dan sejarah profesi kedokteran dengan segala atributnya. Dalam paradigma baru pelayanan kesehatan dan dunia perumahsakitan dewasa ini, dan juga dalam menyongsong era globalisasi, peran para dokter di Rumah Sakit dan hubungannya dengan pihak lain dirumah sakit perlu ditata ulang. Seharusnya memang ada semacam hubungan simbiosis mutualisme dalam hubungan dokter dengan pasien, dengan memperhatikan mutu pelayanan dan kepentingan pasien yang dilayani (Aditama, 2010).

Tabel 1.

Jumlah Kunjungan Pasien Rawat Jalan Tahun 20122014 Di Rumah Sakit Umum Arifin Achmad Pekanbaru

\begin{tabular}{c|c|c}
\hline No & Tahun & $\begin{array}{c}\text { Jumlah Kunjungan } \\
\text { Pasien Rawat Jalan }\end{array}$ \\
\hline 1. & 2012 & 227.296
\end{tabular}




\begin{tabular}{c|c|c}
\hline No & Tahun & $\begin{array}{c}\text { Jumlah Kunjungan } \\
\text { Pasien Rawat Jalan }\end{array}$ \\
\hline 2. & 2013 & 241.146 \\
3. & 2014 & 212.513 \\
\hline & Jumlah & 680.955 \\
\hline
\end{tabular}

Menurut informasi yang didapat dari pegawai Rumah Sakit Umum Daerah Arifin Achmad, penurunan terjadi akibat BPJS. Hal inidikarenakan ada provider lain, peserta BPJS sudah bisa memilih dimana dia akan mendapatkan pelayanan yang terkait dengan kesehatannya dan semenjak adanya BPJS, RSUD Arifin Achmad hanya menerima layanan sekunder dan tersier.

\section{Tabel 2.}

Jumlah Kunjungan Pasien BPJS di Instalasi Rawat Jalan Bulan Januari-Desember Tahun 2014 di Rumah Sakit Umum Arifin Achmad Pekanbaru

\begin{tabular}{ccc}
\hline No & Bulan & JumlahPasien BPJS \\
\hline 1. & Januari & 6.888 \\
2. & Februari & 6.644 \\
3. & Maret & 6.919 \\
4. & April & 7.255 \\
5. & Mei & 7.473 \\
6. & Juni & 8.041 \\
7. & Juli & 6.403 \\
8. & Agustus & 8.102 \\
9. & September & 8.840 \\
10 & Oktober & 8.728 \\
11 & November & 8.692 \\
12 & Desember & 9.467 \\
\hline & Total & 93.452 \\
\hline
\end{tabular}

Sumber: Data sekunder Rekam Medis Rumah Sakit

Dari tabel diatas dapat dilihat bahwa jumlah kunjungan pasien BPJS di instalasi rawat jalan
Rumah Sakit Umum Daerah Pekanbaru setiap bulannya terjadi fruktuasi, Oleh karena itu peneliti tertarik dalam melakukan penelitian kepada pasien BPJS untuk mengetahui faktor apa saja yang mempengaruhi jumlah kunjungan pasien di Instalasi Rawat Jalan RSUD Arifin Achmad Pekanbaru.

\section{METODOLOGI PENELITIAN}

Jenis penelitian ini adalah penelitian analitik kuantitatif, dengan desain cross sectional. Waktu penelitian dilaksanakan pada bulan MeiJuni 2015. Sampel berjumlah 196 orang yaitupasienpeserta BPJS yang berkunjung di Instalasi Rawat Jalan RSUD Arifin Achmad Pekanbaru. Teknik pengambilan sampel adalah Accidental Sampling, pengumpulan data dari data primer dengan membagikan kuesioner. Analisa yang digunakanan adalah univariat dan bivariat, pengolahan data dilakukan dengan menggunakan aplikasi komputer.

\section{HASIL DAN PEMBAHASAN \\ Hasil}

Dari hasil pengumpulan data diperoleh hasil penelitian menunjukkan bahwa ada hubungan yang bermakna antara keterampilan medis Dokter dengan persepsi pasien $\mathrm{p}$ value $=0,005$ ( $\mathrm{p}<$ alpha 0,05), sikap Dokter dengan persepsi pasien $\mathrm{p}$ value $=0,000 \quad(\mathrm{p}<$ alpha 0,05$)$, penyampaian informasi Dokter dengan persepsi pasien $\mathrm{p}$ value $=0,004$ ( $\mathrm{p}<$ alpha 0,05$)$, ketepatan waktu pelayanan Dokter $\mathrm{p}$ value $=$ 0,005 ( $\mathrm{p}<$ alpha 0,05 ).

Tabel 3.

Distribusi Frekuensi Responden Berdasarkan Variabel Penelitian di RSUD Arifin Achmad Pekanbaru

\begin{tabular}{cccc}
\hline No & Variabel Penelitian & Frekuensi & Persentase \\
\hline 1. & KeterampilanMedisDokter & & \\
& TidakBaik & 57 & $29,1 \%$ \\
& Baik & 139 & $70,9 \%$ \\
\hline 2. & Total & 196 & $100 \%$ \\
\hline & SikapDokter & & \\
& TidakBaik & 101 & $51,5 \%$ \\
& Baik & 95 & $48,5 \%$ \\
\hline 3. & Total & 196 & $100 \%$ \\
\hline & PenyampaianInformasiOlehDokter & 114 & $58,2 \%$ \\
\hline
\end{tabular}




\begin{tabular}{cccc}
\hline No & Variabel Penelitian & Frekuensi & Persentase \\
\hline & Baik & 82 & $41,8 \%$ \\
\hline 4. & Total & 196 & $100 \%$ \\
\hline & KetepatanWaktuPelayananDokter & \\
TidakBaik & 125 & $63,8 \%$ \\
Baik & 71 & $36,2 \%$ \\
\hline 5. & Total & 196 & $100 \%$ \\
\hline & PersepsiPasien BPJS & & \\
Tidakbaik & 99 & $50,5 \%$ \\
& Baik & 97 & $49,5 \%$ \\
\hline
\end{tabular}

Sumber: Diolah dari data kuesioner.

\section{Hubungan Keterampilan Medis Dokter Terhadap Persepsi Mutu}

Tabel 4.

Pasien Peserta BPJS di RSUD Arifin Achmad Pekanbaru

\begin{tabular}{|c|c|c|c|c|c|c|c|c|c|}
\hline \multirow{3}{*}{ No } & \multirow{3}{*}{$\begin{array}{c}\text { Keterampilan } \\
\text { Medis }\end{array}$} & \multicolumn{4}{|c|}{ Persepsi Pasien } & \multirow{2}{*}{\multicolumn{2}{|c|}{ Jumlah }} & \multirow{3}{*}{$\begin{array}{c}\text { P } \\
\text { Value }\end{array}$} & \multirow{2}{*}{$\begin{array}{c}\text { POR } \\
95 \% \\
\text { CI }\end{array}$} \\
\hline & & \multicolumn{2}{|c|}{$\begin{array}{l}\text { Tidak } \\
\text { Baik }\end{array}$} & \multicolumn{2}{|c|}{ Baik } & & & & \\
\hline & & $\mathbf{F}$ & $\%$ & $\mathbf{F}$ & $\%$ & $\mathbf{F}$ & $\%$ & & \\
\hline 1. & Tidak Baik & 38 & 66,7 & 19 & 33,3 & 57 & 100 & & 2,557 \\
\hline 2. & Baik & 61 & 43,9 & 78 & 56,1 & 139 & 100 & 0,005 & $(1,342-4,872)$ \\
\hline & Total & 99 & 50,5 & 97 & 49,5 & 196 & 100 & & \\
\hline
\end{tabular}

Tabel 5.

Hubungan Sikap Dokter Terhadap Persepsi Mutu Pasien Peserta BPJS di Instalasi Rawat Jalan RSUD Arifin Achmad Pekanbaru

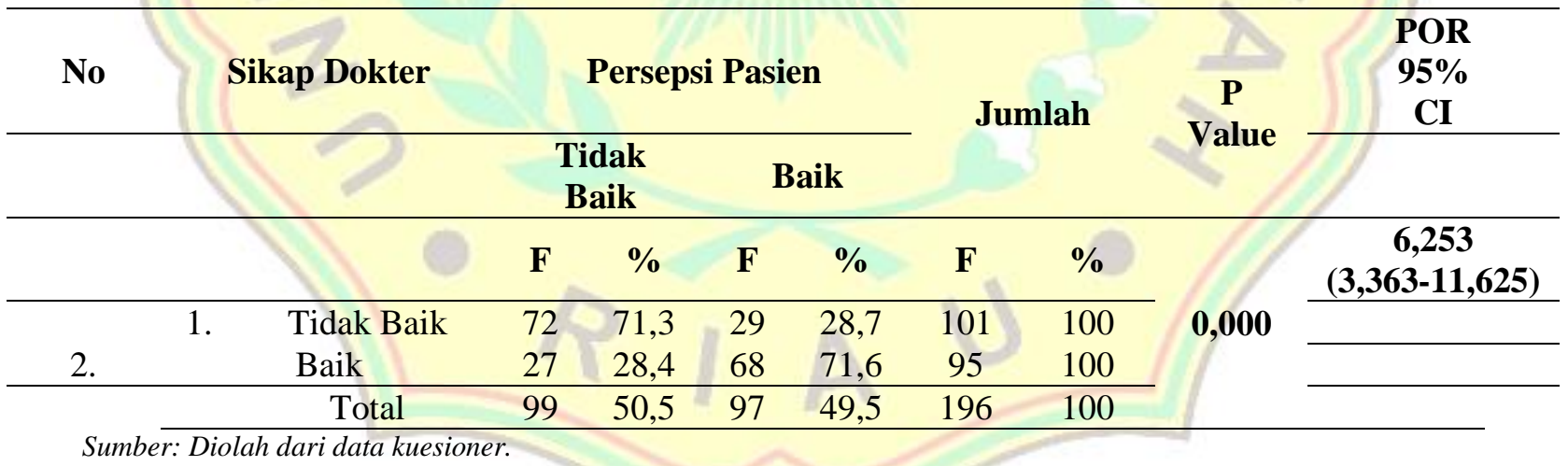

Tabel 6.

Hubungan Penyampaian Informasi oleh Dokter Terhadap Persepsi Mutu Pasien Peserta BPJS di Instalasi Rawat Jalan RSUD Arifin Achmad Pekanbaru

\begin{tabular}{|c|c|c|c|c|c|c|c|c|c|}
\hline \multirow{3}{*}{ No } & \multirow{3}{*}{$\begin{array}{c}\text { Penyampaian } \\
\text { Informasi oleh } \\
\text { Dokter }\end{array}$} & \multicolumn{4}{|c|}{ Persepsi Pasien } & \multirow{2}{*}{\multicolumn{2}{|c|}{ Jumlah }} & \multirow{2}{*}{$\begin{array}{c}P \\
\text { Value }\end{array}$} & \multirow{2}{*}{$\begin{array}{c}\text { POR } \\
95 \% \\
\text { CI }\end{array}$} \\
\hline & & \multicolumn{2}{|c|}{$\begin{array}{l}\text { Tidak } \\
\text { Baik }\end{array}$} & \multicolumn{2}{|c|}{ Baik } & & & & \\
\hline & & $\mathbf{F}$ & $\%$ & $\mathbf{F}$ & $\%$ & $\mathbf{F}$ & $\%$ & \multirow{4}{*}{0,004} & 2,432 \\
\hline 1. & Tidak Baik & 68 & 59,6 & 46 & 40,4 & 114 & 100 & & $(1,358-$ \\
\hline \multirow[t]{2}{*}{2.} & Baik & 31 & 37,8 & 51 & 62,2 & 82 & 100 & & $4,354)$ \\
\hline & Total & 99 & 50,5 & 97 & 49,5 & 196 & 100 & & \\
\hline
\end{tabular}


Tabel 7.

Hubungan Penyampaian Informasi oleh Dokter Terhadap Persepsi Mutu Pasien

Peserta BPJS di Instalasi Rawat Jalan RSUD Arifin Achmad Pekanbaru

\begin{tabular}{|c|c|c|c|c|c|c|c|c|c|}
\hline \multirow{3}{*}{ No } & \multirow{3}{*}{$\begin{array}{c}\text { Penyampaian } \\
\text { Informasi oleh } \\
\text { Dokter }\end{array}$} & \multicolumn{4}{|c|}{ Persepsi Pasien } & \multirow{2}{*}{\multicolumn{2}{|c|}{ Jumlah }} & \multirow[b]{2}{*}{$\begin{array}{c}\mathbf{P} \\
\text { Value }\end{array}$} & \multirow{2}{*}{$\begin{array}{c}\text { POR } \\
95 \% \\
\text { CI }\end{array}$} \\
\hline & & \multicolumn{2}{|c|}{$\begin{array}{l}\text { Tidak } \\
\text { Baik }\end{array}$} & \multicolumn{2}{|c|}{ Baik } & & & & \\
\hline & & $\mathbf{F}$ & $\%$ & $\mathbf{F}$ & $\%$ & $\mathbf{F}$ & $\%$ & \multirow{4}{*}{0,004} & 2,432 \\
\hline 1. & Tidak Baik & 68 & 59,6 & 46 & $\overline{40,4}$ & 114 & 100 & & $(1,358-$ \\
\hline \multirow[t]{2}{*}{2.} & Baik & 31 & 37,8 & 51 & 62,2 & 82 & 100 & & $4,354)$ \\
\hline & Total & 99 & 50,5 & 97 & 49,5 & 196 & 100 & & \\
\hline
\end{tabular}

\section{Pembahasan}

Hubungan Pelayanan Medis Dokter Terhadap Persepsi Mutu Pasien Peserta BPJS

Salah satu dari dimensi mutu pelayanan adalah kompetensi teknis yang termasuk didalamnya seperti pengetahuan kedokteran, keterampilan dan pengalaman, teknologi, keparipurnaan, dan keberhasilan pengobatan. pelayanan dengan keterampilan medis Dokter yang tidak baik beresiko 2 kali untuk menimbulkan persepsi tidak baik kepada pasien BPJS. (95\% CI $(1,342-4,872)$. Hal ini kemungkinan disebabkan karena banyak Dokter yang berpengalaman dalam segala hal seperti dalam pengobatan dan keberhasilan pengobatan, dilihat dari kuisioner, banyak yang mengatakan bahwa Dokter baik dalam melakukan anamnesa, pemeriksaan fisik, serta teliti dalam memeriksa keadaan pasien. Hasil penelitian sejalan dengan penelitian yang dilakukan Hilal Ariadi (2005) yang menyatakan bahwa ada hubungan yang bermakna antara kompetensi teknis Dokter dengan persepsi pasien. jadi diharapkan kepada petugas di Rumah Sakit khususnya Dokter untuk tetap mempertahankan bahkan meningkatkan kompetensi medis.

\section{Hubungan Antara Sikap Dokter} Terhadap Persepsi Mutu Pasien Peserta BPJS

Salah satu dimensi mutu yang penting, empati merupakan syarat untuk peduli, memberikan perhatian pribadi kepada pelanggan, misalnya memberikan perhatian secara khusus kepada setiap pelanggan, kepedulian terhadap keluhan pelanggan, dan pelayanan kepada semua pelanggan tanpa memandang status dan lain-lain.Analisis keeratan hubungan dua variabel diperoleh nilai $\mathrm{POR}=6,253 \quad(95 \%$ CI $(3,363-11,625))$ artinya pelayanan dengan sikap Dokter yang tidak baik beresiko 6 kali untuk menimbulkan persepsi tidak baik kepada pasien BPJS. Penelitian ini sejalan dengan penelitian yang dilakukan oleh Putri Asmita (2008) yang menyatakan bahwa ada hubungan yang bermakna antara persepsi pasien tentang mutu pelayanan sikap Dokter dengan loyalitas pasien. diharapkan kepada petugas kesehatan khusunya Dokter untuk lebih memberi perhatian dan bersikap adil kepada pasien. Karena apabila pelayanan yang dihasilkan berada dibawah harapan maka konsumen merasa kecewa dan berpersepsi tidak baik.

\section{Hubungan Antara Penyampaian Informasi Oleh Dokter Terhadap Persepsi Mutu Pasien Peserta BPJS}

Salah satu hak-hak dari pasien yaitu hak atas informasi, adalah hak pasien untuk mendapatkan informasi dari Dokter, tentang hal-hal yang berhubungan dengan kesehatannya, dalam hal terjadi hubungan Dokter-Pasien. Idealnya isi minimal informasi yang harus disampaikan Dokter adalah diagnose (analisa penyakit menurut pengetahuan kedokteran), resiko dari tindakan medik, alternatif terapi (termasuk keuntungan dan kerugian dari setiap alternatif terapi) dan prognose (upaya penyembuhan). Analisis keeratan hubungan dua variabel diperoleh nilai POR=2,432 (95\% CI $(1,358$ $4,354)$ ) artinya pelayanan dengan penyampaian informasi oleh Dokter yang tidak baik beresiko 2 kali untuk menimbulkan persepsi tidak baik kepada pasien BPJS. Penelitian ini sejalan 
dengan penelitian yang dilakukan oleh Putri Asmita (2008) yang menyatakan bahwa ada hubungan yang bermakna antara persepsi pasien tentang mutu pelayanan penyampaian informasi oleh Dokter dengan loyalitas pasien. diharapkan kepada petugas kesehatan khusunya Dokter untuk lebih memberi banyak informasi kepada pasien yang menyangkut kesehatan pasien itu sendiri.Karena apabila pelayanan yang dihasilkan berada dibawah harapan maka pasien merasa kecewa dan berpersepsi tidak baik.

\section{Hubungan AntaraKetepatan Waktu Pelayanan Oleh Dokter Terhadap Persepsi Mutu Pasien Peserta BPJS}

Menurut Menteri Kesehatan Republik Indonesia Nomor 129/Menkes/SK/II/2008 tentang Standar Pelayanan Minimal Rumah Sakit untuk pelayanan di Rawat jalan jam buka pelayanan adalah jam $08.00 \mathrm{~s} / \mathrm{d} 13.00 \mathrm{Wib}$ setiap hari kerja kecuali Jumat yaitu jam $08.00 \mathrm{~s} / \mathrm{d}$ 11.00 Wib. Analisis keeratan hubungan dua variabel diperoleh nilai $\mathrm{POR}=2,430(95 \% \mathrm{CI}$ $(1,334-4,426))$ artinya pelayanan dengan ketepatan waktu pelayanan oleh Dokter yang tidak baik beresiko 2 kali untuk menimbulkan persepsi tidak baik kepada pasien BPJS. Penelitian ini sejalan dengan penelitian yang dilakukan oleh Putri Asmita (2008) yang menyatakan bahwa ada hubungan yang bermakna antara persepsi pasien tentang mutu pelayanan ketepatan waktu pelayanan oleh Dokter dengan loyalitas pasien. diharapkan kepada manager Rumah Sakit untuk lebih meningkatkan atau memperhatikan kedisiplinan petugas Rumah Sakit khususnya Dokter, terutama disiplin dalam segi waktu seperti datang sesuai dengan jam yang telah ditentukan. Karena apabila pelayanan yang dihasilkan berada dibawah harapan maka pasien merasa kecewa dan berpersepsi tidak baik.

\section{KESIMPULAN}

Pelayanan Dokter yang berhubungan dengan persepsi mutu pasien BPJS adalah keterampilan medis Dokter Analisis keeratan hubungan dua variabel diperoleh nilai $\mathrm{POR}=2,557 \quad(95 \% \mathrm{CI}$ $(1,342-4,872))$ artinya pelayanan dengan keterampilan medis Dokter yang tidak baik beresiko 2 kali untuk menimbulkan persepsi tidak baik kepada pasien BPJS. Sikap Dokter Analisis keeratan hubungan dua variabel diperoleh nilai POR=6,253 (95\% CI $\quad(3,363$ $11,625)$ ) artinya pelayanan dengan sikap Dokter yang tidak baik beresiko 6 kali untuk menimbulkan persepsi tidak baik kepada pasien BPJS. Penyampaian informasi oleh Dokter Analisis keeratan hubungan dua variabel diperoleh nilai $\mathrm{POR}=2,432 \quad(95 \%$ CI $(1,358$ $4,354)$ ) artinya pelayanan dengan penyampaian informasi oleh Dokter yang tidak baik beresiko 2 kali untuk menimbulkan persepsi tidak baik kepada pasien BPJS. Ketepatan waktu pelayanan Dokter Analisis keeratan hubungan dua variabel diperoleh nilai $\mathrm{POR}=2,430 \quad$ (95\% CI $(1,334$ 4,426)) artinya pelayanan dengan ketepatan waktu pelayanan oleh Dokter yang tidak baik beresiko 2 kali untuk menimbulkan persepsi tidak baik kepada pasien BPJS.

\section{DAFTAR PUSTAKA}

Aditama, T,Y. (2010). Manajemen Administrasi Rumah Sakit. Jakarta: Edisi 2, Universitas Indonesia (UI Press).

Alamsyah, D. (2011). Manajemen Pelayanan Kesehatan:materi asuransi kesehatan \& mutu pelayanan kesehatan. Yogyakarta: NuhaMedika.

Al-Assaf, A,F. (2013). Mutu Pelayanan Kesehatan: perspektif internasional. Jakarta: Buku Kedokteran EGC.

Ariadi, H. (2005). Persepsi Pasien terhadap mutu pelayanan Dokter. Eprints.undip.ac.id/17642/1/Hilal_Ariad i.pdf.

Asmita, P. (2008) Analisis Pengaruh Persepsi Pasien tentang mutu pelayanan Dokter. eprints.undip ac.id/17893/1/Putri Asmita.pdf.

Bustami. (2011). Penjaminan Mutu Pelayanan Kesehatan \& Akseptabilitasnya. Padang: Erlangga.

Devisra, Z. (2014). Pengolahan dan Analisa Data dengan SPSS V.13. Pekanbaru: Stikes Hangtuah Pekanbaru 
Kepmenkes. (2008). Standar Pelayanan Minimal Rumah Sakit. Jakarta: Menteri Kesehatan Republik Indonesia.

Kompasiana. (2015). Minim pemahaman Sistem Rujukan BPJS Kesehatan. http://www.jamkesindonesia.com.

Lubis, S. (2008). Konsumen dan pasien. Yogyakarta: Liberty Yogyakarta.

Notoatmodjo, S. (2010) .Metodologi Penelitian Kesehatan. Jakarta: Rineka Cipta.

Notoadmodjo, S. (2012). Metodologi Penelitian Kesehatan. Jakarta: Rineka Cipta.

Nursalam. (2008).Konsepdan Penerapan Metodologi Penelitian Ilmu Keperawatan, Jakarta: Salemba Medika.

Nuruli, R. (2014). Memperoleh Jaminan Sosial dari BPJS Ketenagakerjaan. Jakarta: Visi Media

Pohan, I,S. (2007). Jaminan Mutu Layanan Kesehatan: dasar - dasar pengertian dan penerapan. Jakarta: BukuKedokteran EGC.
Prihantoro, C.R. (2012). Konsep Pengendalian Mutu, Bandung: Remaja Rosdakarya.

Priyoto. (2014). Teori Sikap dan Perilaku dalam Kesehatan. Yogyakarta: Nuha Medika

Rakhmat, J. (2007). Psikologi Komunikasi. Bandung: Remaja Rosdakarya.

Sari, I.D. (2008).Manajemen Pemasaran Usaha Kesehatan. Jogjakarta: Mitra Cendikia Press.

Stikes Hangtuah. (2015). Panduan Skripsi. Pekanbaru: Program Studi Ilmu Kesehatan Masyarakat.

Sulastomo. (2007). Manajemen Kesehatan. Jakarta: PT Gramedia Pustaka Utama.

Uma, H. (2013). Pengertian persepsi. http://m.kompasiana.com. Diakses tanggal 20 Oktober 2013.

Undang - undang kesehatan. (2009). Undang undang kesehatan dan Rumah Sakit. Yogyakarta: Pustaka Yustisia. 